\title{
Factors Influencing Salmonella Contamination and Microbial Load of Beef Carcass at the Yaoundé Slaughterhouse, Cameroon
}

\author{
Chelea Matchawe ${ }^{1}$, Lucy M. Ndip ${ }^{2}$, Anna Zuliani ${ }^{3}$, Marie-Chantal Ngonde $^{1}$ and Edi Piasentier ${ }^{3}$ \\ 1. Institute of Medical Research and Medicinal Plants Studies, Yaoundé, P.O. Box 6163, Cameroon \\ 2 Faculty of Science, University of Buea, Buea, South-West Region, P.O. Box 63, Cameroon \\ 3. Department of Agricultural, Food, Environmental and Animal Sciences, University of Udine, Via Sondrio 2, 33100 Udine
}

\begin{abstract}
Delivering safe beef carcass at the Yaoundé abattoir is challenged by improper Good Manufacturing Practices (GMP) and poor hygiene practices leading to microbial contamination during slaughtering and dressing processes. This study was to estimate the safety and quality of carcasses via detection of Salmonella and evaluation of aerobic colony count (ACC), Enterobacteriaceae count (EC). Swabs of carcass from 145 cattle were collected at three different sites. Hides \& anus from live cattle, butchers' hands, and processing environment were also swabbed. Detection of Salmonella was carried out following ISO 6579. ACC and EC were evaluated using ISO 4833 and ISO 21528-2. Beef carcass registered higher Salmonella prevalence (4.37\%). Generally, microbial load of carcass was beyond FAO microbiological criteria. The post-evisceration carcasses had the highest isolation rate of Salmonella (52.63\%). Both sampling site and seasonal variations had statistically significant impact $(p<0.05)$ on microbial load. Our results reflected poor conditions of slaughtering and inadequate hygienic practices. There is an urgent need for training the abattoir personnel on the GMP and need for the implementation of Hazard Analysis and Critical Control Point (HACCP) principles throughout the slaughtering process at the Yaoundé slaughterhouse.
\end{abstract}

Key words: Beef carcass, ACC, EC, meat quality, Salmonella spp., slaughterhouse.

\section{Introduction}

Safe meat is a requirement for the health of the consumers and for marketing purposes for the food business operators. However, due to its rich protein content and sufficient water activity, meat remains the most perishable of all foods and is consequently highly susceptible to microbial contaminations during slaughtering and dressing processes [1, 2]. The microbial contamination of carcasses in slaugherhouses may be attributed to various sources and influenced by several factors. For instance, this could occur as a result of poor handling and sanitation practices, contact with slaughter facility and equipment, or exposure to other environmental

Corresponding author: Chelea Matchawe, MSc, research scientist, research field: food microbiology. sources such as air and water [3, 4]. Slaughtering procedures such as dressing, trimming and handling of carcass potentially involve many risk factors of both direct and cross-contamination of carcasses [5]. During slaughter, fecal contamination of edible organs with subsequent carrying over to the final carcass is one of the risk factors, which may occur. Consequently, beef carcasses may become important vehicle for foodborne bacteria such as Salmonella spp. in the human food chain [5, 6]. However, microbial contamination of carcass is also influenced by seasonal variation [7]. Microorganisms in meat can cause either its spoilage or food poisoning and food-borne infections in human, leading to economic and health losses [8]. Like in many other African abattoirs, the processing environment and facilities as well as slaughtering and dressing processes in the 
Yaoundé slaughterhouse present potential risks threatening carcass safety and quality. With the exception of the veterinarians on duty, butchers (96\%) are generally without protective clothes during slaughtering [9]. In addition, access of visitors into the slaughterhouse is without restrictive measures such as wearing of protective coats, hand gloves, etc. Moreover, carcasses are not stored in the cooling chamber in order to slow down microbial growth. Slaughter usually starts at midnight but meat retailers only come around 8 a.m. to buy meat. Consequently, carcasses are exposed at room temperature for more than seven hours before delivery. The proliferation of pathogenic bacteria under this conductive environment is highly expected. Given the relevance of monitoring the levels and presence of microorganisms in carcass as important step in Good Manufacturing Practices (GMP) and Hazard Analysis and Critical Control Point (HACCP) programs, the objective of this study was to estimate the potential safety and quality of carcasses produced at the Yaoundé abattoir via determination of aerobic colony count (ACC) and Enterobacteriaceae count (EC) and detection of the presence of Salmonella spp.

\section{Methodology}

\subsection{Study Area}

The study was carried out in Etoudi abattoir located in Etoudi area, one of the popular quarters of Yaoundé, the capital city of Cameroon. It has an annual rainfall of approximately $1,747 \mathrm{~mm}$ with the wet season ranging from March to October interspaced by a month of dry weather in August. The average annual temperature is $23{ }^{\circ} \mathrm{C}$ with peak heat period occurring between December and February whereas July and August being the coldest months. The city of Yaoundé and its surroundings experience four annual seasons: short and long rainy seasons (September-November and March-June, respectively) \& short and long dry seasons (July-August and December-March, respectively). The Etoudi slaughterhouse receives about 6,000 heads of cattle every month giving a monthly beef production estimated at about 1,240 tons [10].

\subsection{Study Population/Facilities}

The study populations were cattle and the butchers. The facilities included abattoir equipment, butchers knives, and water for washing carcasses.

\subsection{Sampling}

Zootechnical information was obtained from the veterinary services prior to cattle selection. Five cattle were randomly chosen once a week for sampling session describing sampling frequency for red meat carcasses. The sampling area for each carcass covered a minimum area of $100 \mathrm{~cm}^{2}$ following the Meat Industry Guide [11]. Areas showing the presence of faeces were preferably swabbed at three sampling sites (post-skinning, post-evisceration and after carcass splitting). In total, 435 swabs of carcass from 145 cattle were collected over 12 months. Moreover, using sterile moistened cotton swabs, hides \& anus from 145 live cattle, butchers' hands (145 butchers), skinning site, evisceration site, splitting site, and store hall (105 samples) were also swabbed to assess cross-contamination of carcass. On the other hand, water $(250 \mathrm{~mL})$ used for washing the abattoir was collected in $250 \mathrm{~mL}$ sterile bottles. The tap was allowed to run for one minute before collecting the water inside the sampling bottle. Water samples were collected once a month.

\subsection{ACC and EC}

Sterile cotton swabs moistened with sterilized distilled water from hide \& anus, from carcasses after skinning, evisceration, splitting, and final dressing steps as well as swabs from the skinning site, evisceration site, splitting site, storage hall and butchers' hands were transferred into nutrient agar (NA) and Mackonkey agar (MAC) for incubation at $37 \pm$ $1{ }^{\circ} \mathrm{C}$ for $18-24 \mathrm{~h}$ for ACC and EC following ISO 4833 
and ISO 21528-2 respectively [12, 13]. Water samples were filtered into the above media using membrane filtration method [14].

\subsection{Isolation and Identification of Salmonella spp.}

The procedure for isolation of Salmonella spp. was based on the horizontal method for the detection of Salmonella spp. according to ISO 6579 [15] with the following modification: Rappaport Vasiliadis (RV10) and Selenite (SB) broths were used as enrichment media instead of Rappaport Vasiliadis (RV10) Muller-Kauffmann tetrathionate/novobiocin broth (MKTTn) broths. Suspect colonies of Salmonella on XLD and on SS agar plates were selected and individually spread into NA for an incubation period of $24 \pm 3$ hours at $37 \pm 1{ }^{\circ} \mathrm{C}$ as pure cultures. Pure colonies were then tested for Gram reaction and preliminary biochemical reactions including urease production, indole formation, hydrogen sulphide production and carbohydrate fermentation (on TSI agar), Voges-Proskauer (VP) reaction, motility, indole on sulfide indole motility (SIM) medium, oxidase and citrate utilization.

All Salmonella isolates were confirmed using Galerie API-20 E (BioMérieux, France) and real-time Polymerase Chain Reaction (PCR) using invA gene [16].

\subsection{Statistical Analysis}

One-way analysis of variance (ANOVA) was used to test the percentage of rejected carcasses following the FAO microbiological criteria as well to test the influence of both sampling site and seasonal variation on microbial load at $5 \%$ confidence limit.

\subsection{Ethical Considerations}

Approval of the study, its design, data collection tools and consent forms were obtained from the Ethics Review and Consultancy Committee of the Cameroon Bioethics Initiative (CAMBIN).

\section{Results and Discussion}

\subsection{Evaluation of Microbial Load of Swab Samples}

Results in Fig. 1 generally describe the microbial load of different samples collected at the Yaoundé abattoir between December 2014 and November 2015. Beef carcass had the highest microbial load for both ACC and EC (7.43 and $6.44 \log _{10} \mathrm{cfu} / \mathrm{cm}^{2}$ respectively) seconded by butchers' hands for AAC (7.37 $\log _{10}$ $\mathrm{cfu} / \mathrm{cm}^{2}$ ). On the other hand, live cattle presented the second highest level of contamination of beef carcass in terms Enterobacteriaceae count $\left(5.47 \log _{10} \mathrm{cfu} / \mathrm{cm}^{2}\right)$ whereas the abattoir environment registered the least microbial load both for ACC and EC levels (5.12 \& $3.22 \log _{10} \mathrm{cfu} / \mathrm{cm}^{2}$ ) respectively.

The relatively high microbial load of both beef carcasses and butchers' hands is attributed to poor hygiene and slaughter practices during slaughter process. With the exception of the veterinarians on duty, butchers were mostly illiterate $(76 \%)$, and the majority of them ((92\%) were without protective clothes and hand gloves (96\%) during slaughtering [9]. As a result, the high microbial load of their naked hands

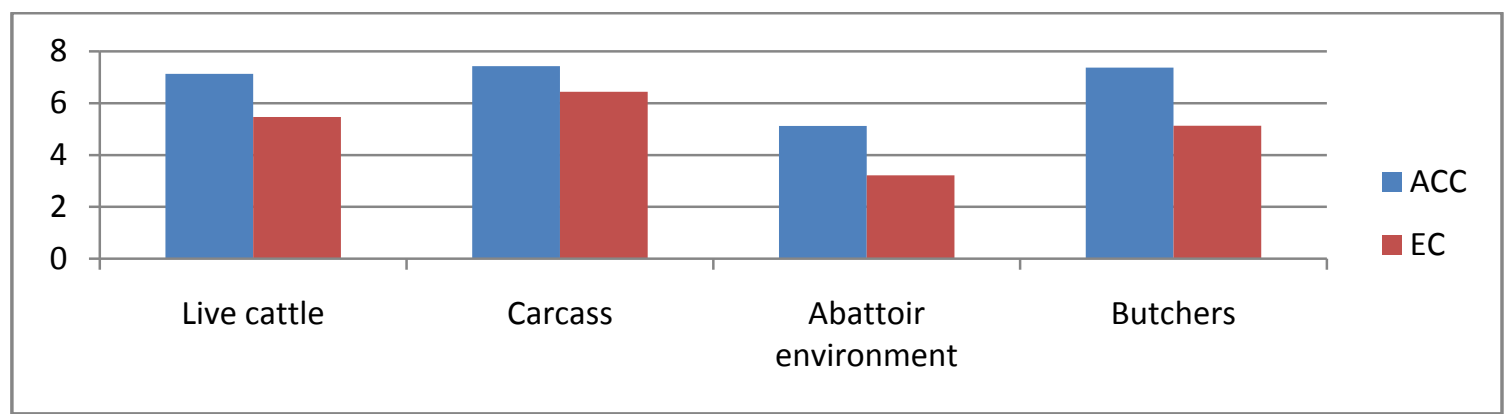

Fig. 1 The annual ACC and EC levels of swabs from cattle, beef carcass, butchers and abattoir environment. 
might be attributed to contact with carcasses and other body parts during operations. As reported by Bhandare and teammates [17], butchers also used to push knives into their pant belts directly touching the backside. Additionally, butchers did not wash their knives intermittently between the operations. Moreover, carcass handlers did not sanitize their hands or hand tools. Other lapses attributed to bad slaughter practices observed during the whole slaughter process included improper skinning, non-removal of visible fecal contamination from carcasses, unsanitary trimming process, non-use of hot water or sanitizer during carcass splitting and manual pulling of carcasses in the process of storing meat. Improper skinning would transfer dirt and faeces from the hides and skin to the neck area of the carcass. This practice was common at the Yaoundé slaughterhouse and underlines evident lack of training of butchers on GMP. On the other hand, trimming which is normally intended to remove fecal and ingesta contamination [1] was wrongly used by butchers who exploited this process for serving themselves with portions of meat. This caused too many hands to be on the carcasses. In addition, the splitting saw was occasionally left unclean in some slaughtering days. Moreover, during carcass splitting, water was released just enough to distribute microbial contaminants to other area of carcass. Normally, after this step, carcass washing (with $82{ }^{\circ} \mathrm{C}$ hot water) recommended by the FAO/WHO [1] is carried out to address any previous slaughter lapses. These discrepancies were similarly noted in an Ethiopian abattoir [6]. Upon all these gaps, meat handlers pulled the final processed carcasses manually to the storage room. Under these poor slaughter practices, cross-contamination of carcasses with human pathogens was likely to occur. Moreover, other poor slaughter practices included high frequency of visible fecal matter on post-evisceration carcasses witnessing rupture of the visceral content during evisceration. Sanitization of the abattoir equipment and environment in the Yaoundé abattoir was reduced to a simple post slaughter cleaning of the floor, equipment and abattoir's facilities with tap water. The relatively high EC of hide and anal swabs of live cattle may be attributed to pre-slaughter factors such as physical stress because of long distances during transportation, overcrowding in lairage, health and cleanliness conditions of the animals on the day of slaughter and climatic factors more particularly rain during the slaughter time. In fact, 8.46 and $35.4 \%$ of the slaughtered cattle came from Adamawa and East regions (400 and 700 from Yaoundé) respectively spending more than 18 and 5 hours on the way during transportation. Accordingly, cattle destined for slaughter should not be transported continuously over 10 hours [3]. The cleanliness of the animal on the day of slaughter is an important factor that favors the contamination of carcasses. Serraino et al. [18] reported that increasing dirt on cattle was associated with higher ACC and EC on hide and carcasses. Moreover, rainfall on the slaughter day increases wetness in the lairage causing cattle to rub themselves with fecal matter.

\subsection{Annual Microbial Load of Beef Carcass according to Sampling Site}

Results in Fig. 2 show the annual means $\log _{10}$ ACC and $\log _{10}$ EC of beef carcasses. Post-evisceration carcasses presented the highest microbial load both for ACC and EC (7.56 \& $\left.6.81 \log _{10} \mathrm{cfu} / \mathrm{cm}^{2}\right)$ followed by the finally dressed carcass $\left(7.45 \& 6.52 \mathrm{cfu} / \mathrm{cm}^{2}\right.$ for $\log _{10}$ ACC and $\log _{10}$ EC respectively). On the other hand, post-skinned carcasses had the least ACC and EC (7.28 \& $\left.5.98 \log _{10} \mathrm{cfu} / \mathrm{cm}^{2}\right)$.

The highest contamination of post-eviscerated carcasses may be more likely attributed to poor slaughter practice due to frequent rupture of the visceral content during evisceration. However, the heavy contamination of the finally dressed carcass reflects poor hygiene practices and evidence of cross-contamination. Butchers via their pulling activity may be the greatest contributors at this level. 
The high microbial load of the finally dressed carcasses may be also due to the absence of sanitizing and decontamination procedures. Moreover, beyond the evisceration site, carcasses swabbed at other sampling sites obviously presented higher microbial load. This may underline in addition to failure to meet good slaughtering practices, the absence or existence of poor hygiene practices in the abattoir. On the other hand, the mean Enterobacteriaceae count of carcasses at different sampling sites appeared unexpectedly very high (Fig. 2) varying between $5.98 \log _{10} \mathrm{cfu} / \mathrm{cm}^{2}$ and $6.81 \log _{10} \mathrm{cfu} / \mathrm{cm}^{2}$. These results are far beyond the microbiological criteria defined by the Meat Industry Guide setting the limit for the acceptable Enterobacteriaceae count for beef carcass [11].

\subsection{Classification and Quality Assessment of Beef Carcass Based on Mean ACC and EC}

Table 1 describes the classification and quality assessment of beef carcasses based on aerobic colony and Enterobacteriaceae counts. More than 94\% and 95\% of all carcasses (data not shown) at different processing steps had ACC and EC levels greater than 6 and $1.8 \log _{10} \mathrm{cfu} / \mathrm{cm}^{2}$ respectively, far beyond the recommended standard. Post-evisceration carcasses recorded highest percentage $(97.6 \%$ and 99.2$)$ of carcasses that fell under the unaccepted category both in terms of ACC and EC levels.

Once more, these results reinforce the importance of evisceration process as the principal route of microbial contamination of carcasses. These results are in accordance with the findings of Ahouandjnou and colleagues [19] who attributed a high aerobic mesophilic count in carcasses to bad evisceration practices. One of the most frequently occurring bad evisceration practices was the rupture of the gastro-intestinal tract [19]. Bad evisceration practice in itself is an expression of poor slaughter practice. Ideally, not more than $60 \%$ of analyzed carcasses should exceed $6 \log _{10} \mathrm{cfu} / \mathrm{cm}^{2}$ in terms of ACC [11]. However, the acceptable mean $\log _{10} \mathrm{cfu} / \mathrm{cm}^{2}$ for total viable count and Enterobacteriaceae count should be equal to or lesser than 4.3 and $1.8 \log _{10} \mathrm{cfu} / \mathrm{cm}^{2}$ respectively. Unfortunately, even the least mean $\log _{10}$

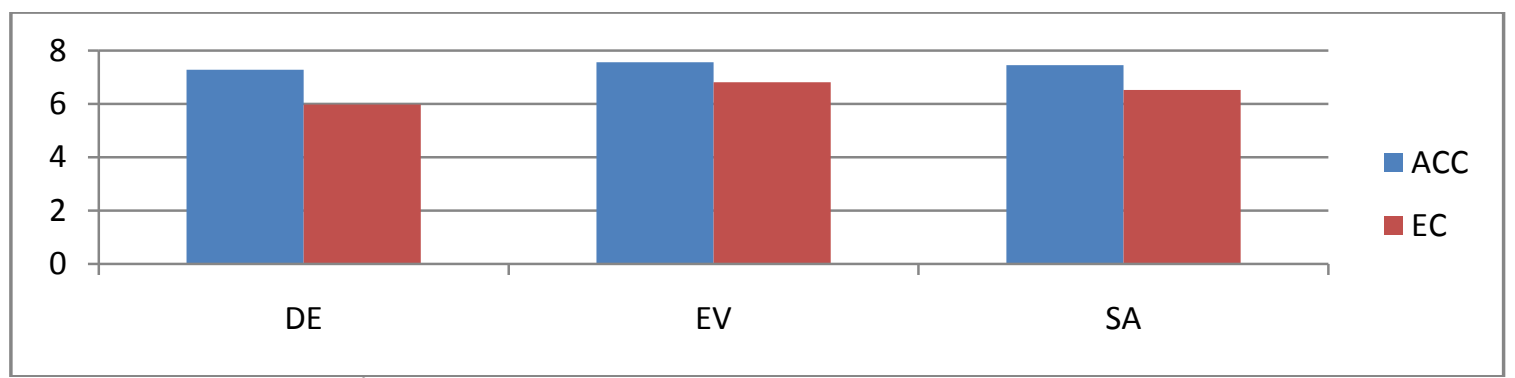

Fig. 2 Annual mean $\log 10 \mathrm{cfu} / \mathrm{cm}^{2}$ of beef carcass from the Yaoundé abattoir.

$\mathrm{DE}=$ post-skinned carcass, $\mathrm{EV}=$ post-evisceration carcass, $\mathrm{SA}=$ carcass after final dressing.

Table 1 Classification of carcass samples based on Aerobic ACC \& EC $\left(\log _{10} \mathbf{c f u} / \mathrm{cm}^{2}\right)$.

\begin{tabular}{lllll}
\hline Indicator & $\begin{array}{l}\text { Carcass category } \\
\left(\log _{10} \mathrm{cfu} / \mathrm{cm}^{2}\right)\end{array}$ & $\mathrm{DE}(\%)$ & $\mathrm{SA}(\%)$ & $\mathrm{EV}(\%)$ \\
\hline ACC & $4>\mathrm{X} \leq 5$ & 1.6 & 0.8 & 0.0 \\
EC & $\mathrm{X} \leq 0.8$ & 8.8 & 4.0 & 0.8 \\
ACC & $5>\mathrm{X} \leq 6$ & 7.2 & 4.0 & 2.4 \\
EC & $\mathrm{X} \leq 1.8$ & 0.0 & 0.0 & 0.0 \\
ACC & $>6$ & 91.2 & 95.2 & $97.6^{* *}$ \\
EC & $\mathrm{X}>1.8$ & 91.2 & 96.0 & $99.2^{* *}$ \\
& Mean & 7.28 & 7.45 & 7.56 \\
\hline
\end{tabular}

**Statistically significant $(p<0.05)$. 
ACC of beef carcass in this present study was beyond $7.0 \log _{10} \mathrm{cfu} / \mathrm{cm}^{2}$. In addition, following the FAO Microbiological Standard [20], most of the carcasses produced at the Yaoundé slaughterhouse are classified under unacceptable category. According to FAO, a safe level of aerobic plate count should be equal to or lesser than $4 \log _{10} \mathrm{cfu} / \mathrm{g}$; when ACC lies between 4 $\log _{10} \mathrm{cfu} / \mathrm{cm}^{2}$ and $5 \log _{10} \mathrm{cfu} / \mathrm{cm}^{2}$, the resulting carcass is considered to be under critical condition; whereas when the total viable bacterial contamination level is more than $5 \log _{10} \mathrm{cfu} / \mathrm{cm}^{2}$, the meat is qualified as unacceptable for human consumption. Caselani and others [8] equally reported a higher rate (62.9\%) of rejected slaughtered beef carcasses on the basis of total viable count $\left(\log _{10} \mathrm{cfu} / \mathrm{cm}^{2}\right)$.

High mean ACC (> $\left.6 \log _{10} \mathrm{cfu} / \mathrm{cm}^{2}\right)$ indicates meat spoilage (loss of some organoleptic properties due to the high presence of spoilage organisms). In essence, aerobic colony count (ACC) is a measure of microbial quality of the carcass [2]. Since ACC provides an estimate of overall bacterial population, higher ACC usually indicates poorer quality and a reduced shelf-life of carcasses [21]. Similar high microbial contamination in beef carcasses was described by Ahmad et al. [2]. While high levels of aerobic colony count lead to reduced shelf-life of meat due to increased activities of spoilage organisms, excessive contamination of carcasses with Enterobacteria is of public health concern. Enterobacteriacae including Salmonella, Yersinia and E. coli O157, is a group of bacteria that live predominantly in the intestines of animals. Most enterobacteria are food-borne pathogens, frequently involved in food infections or food poisoning. The presence of these organisms on the surface of carcasses reveals faecal and environmental contamination indicating poor hygiene practices or poor meat handling practices [1, 11]. These results reveal the poor quality and hygiene of carcasses manufactured at the Yaoundé abattoir. There is therefore an urgent need for the implementation of HACCP principles throughout the slaughter process at the Yaoundé abattoir.

\subsection{Evaluation of Microbial Load of the Processing Environment}

The annual microbial load of the processing environment was described (data not shown). Surfaces of evisceration site registered the highest microbial load both for the mean ACC (6.96 $\left.\log _{10} \mathrm{cfu} / \mathrm{cm}^{2}\right)$ and EC (4.66 $\left.\log _{10} \mathrm{cfu} / \mathrm{cm}^{2}\right)$ while water was the least contaminated environmental samples both for ACC $\left(1.90 \log _{10} \mathrm{cfu} / \mathrm{mL}\right)$ and EC $\left(0.19 \log _{10} \mathrm{cfu} / \mathrm{cm}^{2}\right)$. The highest annual means of ACC and EC registered by the evisceration site indicate the consistence of the evisceration process to appear as the key route of microbial contamination at the slaughterhouse. A good evisceration process will eventually lead to a significant reduction of microbial load of carcasses. Though the ACC levels of the processing environment were relatively high (1.90-6.96 $\left.\log _{10} \mathrm{cfu} / \mathrm{cm}^{2}\right)$, its EC counts were moderately expressed and were comparatively similar to other findings which reported the mean ACC from $3.08 \log _{10} \mathrm{cfu} / \mathrm{mL}$ to $6.70 \log _{10}$ $\mathrm{cfu} / \mathrm{cm}^{2}$ for water and slaughterhouse floor respectively [17]. The high ACC levels (6.96 $\log _{10}$ $\mathrm{cfu} / \mathrm{cm}^{2}$ ) recorded from the evisceration site in the present study indicate its potential as important route for microbial contamination of carcass.

However, the exceptionally high microbial contamination of both carcasses and processing environments in general with the exception of drinking water reinforces the importance of controlling the entire slaughtering process and the imperative for implementing HACCP principles. The decontamination of carcasses is recommended to decrease the contamination of pathogens which may be present on meat products, and to avoid post-slaughter environmental contamination. Moreover, a simple and economical microbiological method useful in testing the effectiveness of sanitizing procedures to test a likely presence of pathogens in the slaughterhouse environment is also needed. 
3.5 Seasonal Variation of Microbial Load of Carcass and the Processing Environment between December 2014 and November 2015

Microbial load in terms of ACC and EC for both carcass and abattoir environment was higher during rainy season than in dry season. In addition to sampling site, seasonal variation had statistically significant impact $(p<0.05)$ on both ACC and EC for carcasses and processing environment. Equally, Caselani and teammates [8] made similar observation concerning total viable count $(p \leq 0.05)$. For them, the difference was due to a rise in temperature and humidity during summer promoting microbial multiplication. Generally, the relative increase for ACC and EC in wet season compared to dry season may be mainly attributed to rainfall which in return would directly influence the relative humidity at rainy season. This could logically justify the relatively higher microbial load in rainy seasons compared to that of dry seasons. It could also be due to poor cleanliness condition of cattle resulting from rainfall prior to slaughter as rain plays an important role in the development of water-borne pathogens [22]. This is the opinion of Çalicioğlu and colleagues [23] who indicated that not only rainfall constitutes a transmission vehicle but also a supplier of essential moisture to the enteric microorganisms facilitates their survival in the environment. Similarly, with respect to seasonal variation, Hutchison and teammates [24] reported that beef carcasses had significantly higher numbers of total aerobes and Enterobacteriaceae in late summer and early autumn.

3.6 Detection of Salmonella spp. from Live Cattle, Beef Carcasses, Butchers and Processing Environment

Results of culture-based detection of 23 Salmonella isolates from 830 swab samples yielded the Salmonella overall prevalence of $2.8 \%$ at the Yaoundé abattoir. Based on sample category, the prevalence rates of Salmonella for live cattle, beef carcass, processing environment and butchers' hands were 0.69\%, 4.37\%, $1.9 \%$ and $0.69 \%$ respectively (Fig. 3).

The highest detection rate of Salmonella in beef carcass indicates poor manufacturing and hygiene practices. The isolation of Salmonella strains from butchers' hands, and surfaces of skinning and evisceration site underlines the risk of cross-contamination of carcasses in the course of slaughter and handling processes. In addition, the detection of Salmonella spp. from the processing environment may also be attributed to the absence of post-slaughter decontamination and sanitizing interventions at the Yaoundé abattoir. However, the relatively low overall prevalence of Salmonella in the present study (2.8\%) is likely attributed to the loss of half (50 cases) of the Salmonella suspects due to light failure when the laboratory was undergoing renovation

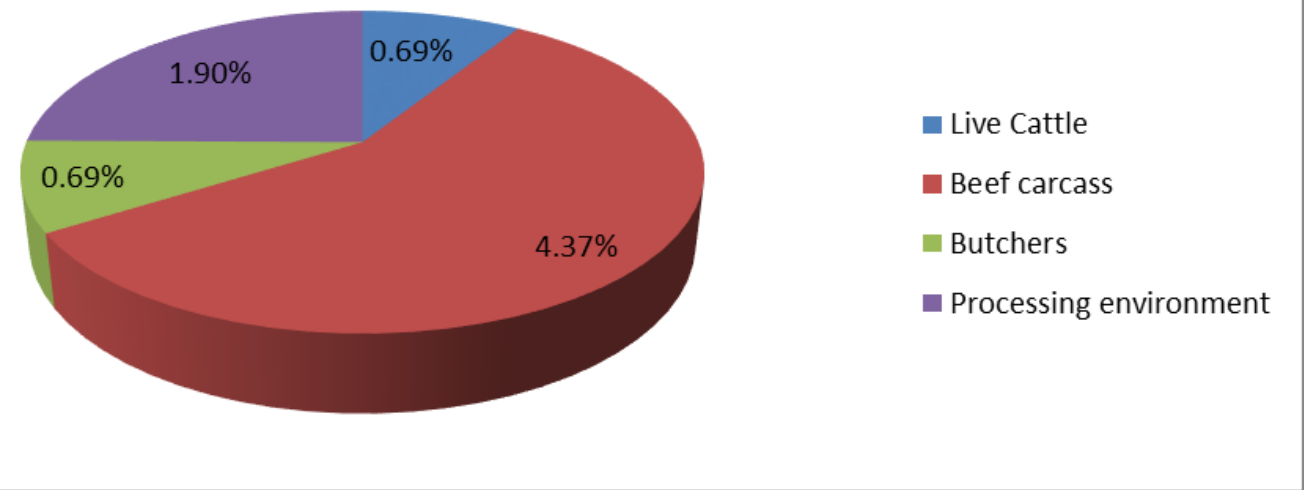

Fig. 3 Culture-based prevalence of Salmonella per sample category. 


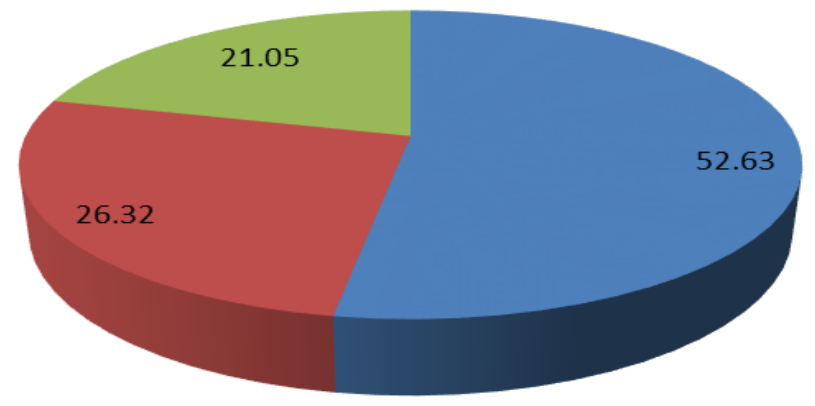

Fig. 4 Culture-based isolation rate of Salmonella in beef carcass per sampling site.

work. Our results are closer to the findings of Tadesse and Gebremedhin [5] who reported lower prevalence rate of Salmonella spp. in beef carcass (6\%). The Salmonella isolation rate for live cattle was extremely low $(0.69 \%)$ in the present study compared to a study published in 2016 which reported $10.7 \%$ in live cattle [25]. Similarly, lower prevalence rate of Salmonella among butchers was expressed in the present study compared to the findings of several authors [4]. On the other hand, as shown in many studies, Salmonella spp. are not easily isolated in the processing environment. The present research work registered a prevalence rate of $0.69 \%$ for this pathogen in the processing environment. These results are far from those described by two research teams who reported an isolation rate of $1.85 \%$ and $2-7.01 \%$ of Salmonella spp. from the surfaces of the processing environment which included the skinning site, evisceration site, splitting saw and the hooks and hangers of the dressing hall [4, 17]. Moreover, higher prevalence (31.1\%) of Salmonella has also recently been reported by Faleke and co-investigators in 2017 [26]. No Salmonella spp. were isolated from water sample used for cleaning the abattoir as reported by a group of researchers in 2016 [27]. Some differences in results compared to other studies may be due to the nature of the abattoir design, species of the slaughtered cattle, animals' age, slaughtering practices, sanitation practices, and sampling procedure, frequency and time of sampling, transport and storage of samples and methods of isolation of Salmonella.

On the basis of sampling site, the pre-eviscerated carcasses experienced the greatest isolation rate of Salmonella (52.63\%) followed by the finally dressed carcasses (26.32\%) while the post-skinned beef carcasses were least Salmonella contaminated (21.05\%) as seen in Fig. 4.

The highest detection rate of Salmonella of the post-eviscerated carcasses can be mostly attributed to bad evisceration practices, often resulting in rupture of the gastro-intestinal tract or as a result of hide-to-carcass contamination transfer. Moreover, the importantly high isolation rate of Salmonella from the finally processed carcasses may be attributed not only to poor hygiene practices but also to handling and pulling activities of butchers, and to bacteria dissemination following water splashing during halving of carcass. This might encourage cross-contamination resulting in this high detection rate of Salmonella at this stage of the slaughtering process. This also underlines the importance of health risk associated with the final slaughter products at the Yaoundé abattoir.

\section{Conclusion}

Generally, microbial contamination of carcasses at the Yaoundé abattoir was relatively high both in terms of aerobic colony count (ranging from 7.13-7.56 $\log _{10}$ $\left.\mathrm{cfu} / \mathrm{cm}^{2}\right)$ and Enterobacteriaceae count (5.47-6.81 $\log _{10} \mathrm{cfu} / \mathrm{cm}^{2}$ ) respectively. More than $97 \%$ carcasses 
at post-evisceration had ACC levels greater than 6 $\log _{10} \mathrm{cfu} / \mathrm{cm}^{2}$ far beyond the recommended limits fixed by FAO standard and Meat Industry Guide laying down the microbiological criteria for beef carcass. Globally carcasses manufactured at the Yaoundé slaughterhouse were rated unacceptable based on these criteria. Though the ACC levels of the processing environments were relatively high (1.90-7.37 $\left.\log _{10} \mathrm{cfu} / \mathrm{cm}^{2}\right)$, their EC counts were moderately expressed $\left(0.19-5.13 \log _{10} \mathrm{cfu} / \mathrm{cm}^{2}\right)$. The highest levels of ACC \& EC for post-evisceration carcasses and evisceration site indicate that evisceration process is the most important critical control point of the slaughtering process. Both sampling site and seasonal variations had statistically significant impact $(p<0.05)$ on both ACC and EC levels. With the exception of rainfall ( $p \leq 0.05$ ), no statistically significant difference was recorded between rainy and dry season in terms of meteorological factors. Though a relatively low prevalence (2.8\%) of Salmonella was recorded in the course of this study, the highest isolation (4.37\%) of this pathogen in beef carcass compared to other samples poses a serious risk of cross-contamination of carcasses with human pathogens. Our results reflect poor conditions of carcasses slaughtering and handling, and inadequate hygienic practices at the Yaoundé slaughterhouse. Achieving meat hygiene requires therefore personal hygiene, slaughter and meat processing hygiene, hygiene of slaughter and meat processing premises \& equipment. In the light of these findings, there is an urgent need for training the abattoir personnel on the Good Manufacturing Practices and need for the implementation of HACCP principles throughout the slaughter process for this slaughterhouse.

\section{Acknowledgments}

This study was partially funded by the International Atomic Energy Agency (IAEA) under CMR/6010 project. We thank the University of Udine (Italy) for providing Qiagen extraction kit and real-time PCR reagents.

\section{Conflict of Interest}

The authors have no conflicts of interest to declare.

\section{References}

[1] FAO/WHO. 2016. Interventions for the Control of Non-typhoidal Salmonella spp. in Beef and Pork: Meeting Report and Systematic Review. www.who.int/foodsafety.

[2] Ahmad, M. U. D., Sarwar, A., Najeeb, M. I., Nawaz, M., Anjum, A. A., Ali, M. A., and Mansur, N. 2013. "Assessment of Microbial Load of Raw Meat at Abattoirs and Retail Outlets." The Journal of Animal \& Plant Sciences 23 (3): 745-8.

[3] Mummed, Y. Y. 2015. "Beef Carcass Quality, Yield and Causes of Condemnation in Ethiopia." $\mathrm{PhD}$ thesis, University of Pretoria.

[4] Kahraman, T., Cetin, O., Dumen, E., and Buyukunal, S. K. 2010. "Incidence of Salmonella spp. and Listeria monocytogenes on Equipment Surfaces and Personnel Hands in Meat Plants.” Revue Méd. Vét. 161 (3): 108-13.

[5] Tadesse, G., and Gebremedhin, E. Z. 2015. "Prevalence of Salmonella in Raw Animal Products in Ethiopia: A Meta-analysis.” BioMed Central Research Notes 21 (8): 163.

[6] Hailesellasie, M., Tadele, H., Adhana, K., and Kalayou, S. 2013. "Food Safety Knowledge and Practices of Abattoir and Butchery Shops and the Microbial Profile of Meat in Mekelle City, Ethiopia.” Asian and Pacific Journal of Trop Biomedicine 3: 407-12.

[7] Caselani, K., Prata, L. F., Prata, C. B., Bizari, P. A., and Pereira, G. T. 2013. "Relationship between HACCP Controls Pathogen Reduction Program and Meat Quality during Cattle Slaughter Process: One-Year Survey in a Brazilian Exporting Abattoir.” Revista Portuguesa de Ciencia Veterinarias 108 (585-586): 29-38.

[8] Komba, E. V. G., Komba, E. V., Mkupasi, E. M., Mbyuzi, A. O., Mshamu, S., Luwumbra, D., et al. 2012. "Sanitary Practices and Occurrence of Zoonotic Conditions in Cattle at Slaughter in Morogoro Municipality, Tanzania: Implications for Public Health.” Tanzania Journal Health Research 14 (2). dx.doi.org/10.4314/thrb.v14i2.6.

[9] Matchawe, C., Ndip, L. M., Zuliani, A., Tsafack, J. J. T., Nsawiret, B. J., et al. 2019. "Knowledge, Attitude and Practices Regarding Food Safety and Sanitation among Carcass Handlers Operating at the Yaoundé Slaughterhouse, Cameroon.” International Journal of Advanced Research and Publications, ISSN 2456-9992, 

at the Yaoundé Slaughterhouse, Cameroon

www.ijarp.org.

[10] Bawe, N. M. 2014. “Carcass Evaluation of Indigenous Cattle Breeds Salughtered at the SODEPA Slaughterhouse, Yaoundé-Cameroon.” $\mathrm{PhD}$ thesis, University of Dschang.

[11] Anon. 2015. Meat Industry Guide Microbiological Criteria. Chapter 13, pp. 1-32.

[12] ISO. 2013. ISO 4833-1:2013. Microbiology of the Food Chain-Horizontal Method for the Enumeration of Microorganisms-Part 1: Colony Count at $30^{\circ} \mathrm{C}$ by the Surface Spread Technique.

[13] ISO. 2004. ISO 21528-2:2004. Horizontal Method for the Enumeration of Enterobacteriaceae-Part 2: Colony Count at $37^{\circ} \mathrm{C}$ by the Surface Spread Technique.

[14] National Academy of Science. 2004. "Indicators for Water Borne Pathogens.” National Academies Press. http://www.nap.edu/catalog/11010.html.

[15] ISO. 2002. ISO 6579:2002. Microbiology of Food and Animal Feeding Stuffs-Horizontal Method for the Detection of Salmonella spp. Geneva: International Organization for Standardization.

[16] Malorny, B., Hoorfar, J., Hugas, M., Heuvelink, A., Fach, P., Ellerbroek, L., Bunge, C., Dorn, C., and Helmuth, R. 2003. "Interlaboratory Diagnostic Accuracy of a Salmonella Specific PCR-based Method.” International Journal of Food Microbiology 89: 241-9.

[17] Bhandare, S. G., Paturkar, A. M., Waskar, V. S., and Zende, R. J. 2009. "Bacteriological Screening of Environmental Sources of Contamination in an Abattoir and the Meat Shops in Mumbai, India.” Asian Journal Food Agricultural Industry 2 (3): 280-90.

[18] Serraino, A., Bardasi, L., Riu, R., Pizzamiglio, V., Liuzzo, G., Galletti, G., et al. 2012. "Visual Evaluation of Cattle Cleanliness and Correlation to Carcass Microbial Contamination during Slaughtering." Meat Science 90: 502-6.

[19] Ahouandjnou, H., Baba-Moussa, F., Bonou, J., Dougnon, V., Adéoti, Z., Yedji, R., et al. 2015. "Evaluation of the Microbiological Quality of Cattle Carcasses in Some Slaughterhouses at Benin, West Africa.” International Journal of Scientific Reports 1 (5): 228-34.
[20] FAO. 2007. "Meat Processing Technology for Small-to-Medium-Scale Producers.” Accessed 14/6/2012. http://www.fao.org/docrep/010/ai407e/ai407e00.htm.

[21] Alamin, S. A., and Ahmed, D. A. 2015. "A Study of Total Bacterial Count and Organoleptic Examination of Different Types of Sausages in the Sudan.” Journal of Agriculture and Veterinary Science 8 (8): 18-23.

[22] Jofre, J., Blanch, A. R., and Lucena, F. 2010. "Water-Borne Infectious Disease Outbreaks Associated with Water Scarcity and Rainfall Events.” In Water Scarcity in the Mediterranean: Perspectives under Global Change, edited by Sabater, S., and Barcelo, D.

[23] Çalicioğlu, M., Buege, D. R., and Luchansky, J. B. 2010. "Effect of Pre-evisceration, Skin-On Carcass Decontamination Sanitation Strategies for Reducing Bacterial Contamination of Cattle during Skinning." Turkish Journal of Veterinary and Animal Science 34 (3): 261-6.

[24] Hutchison, M. L., Thomas, D. J., Small, A. H., Buncic, S., and Howell, M. 2007. "Implementation of Compulsory Hazard Analysis Critical Control Point System and Its Effect on Concentrations of Carcass and Environmental Surface Bacterial Indicators in United Kingdom Red Meat Slaughterhouses." Journal of Food Protection 70 (7): 1633-9.

[25] Beyene, T., Yibeltie, H., Chebo, B., Abunna, F., Beyi, A. F., Mammo, B., et al. 2016. "Identification and Antimicrobial Susceptibility Profile of Salmonella Isolated from Selected Dairy Farms, Abattoir and Humans at Asella Town, Ethiopia.” J. Vet. Sci. Techno. 7: 3.

[26] Faleke, O. O., Jolayemi, K. O., Igoh, Y. O., Jibril, A. H., and Ayedun, J. O., 2017. "Salmonella Species on Meat Contact Surfaces and Processing Water in Sokoto Main Market and Abattoir, Nigeria.” Macedonian Veterinary Review 40 (1): i-vii.

[27] Madoroba, E., Kapeta, D., and Gelaw, A. K. 2016. "Salmonella Contamination, Serovars and Antimicrobial Resistance Profiles of Cattle Slaughtered in South Africa." Onderstepoort Journal of Veterinary Research 83 (1): 1109. 